\title{
Sample Pretreatment Using Chitosan-based Chelating Resin for the Determination of Trace Metals in Seawater Samples by Inductively Coupled Plasma-Mass Spectrometry
}

\author{
Rosi Ketrin Katarina,* Toshio Takayanagi,* Koji Oshita, ** Mitsuko Oshima,* and \\ Shoji МотомIZU* \\ *Department of Chemistry, Faculty of Science, Okayama University, \\ 3-1-1 Tsushimanaka, Okayama 700-8530, Japan \\ **Department of International Conservation Studies for Cultural Properties, Faculty of Cultural Properties, \\ Kibi International University, 8 Iga, Takahashi, Okayama 716-8508, Japan
}

\begin{abstract}
A sample-pretreatment method using a chitosan-based chelating resin, ethylenediamine- $N, N, N^{\prime}$-triacetate-type chitosan (EDTriA-type chitosan), was developed for the preconcentration of trace metals in seawater and separation of the seawater matrix prior to their determination by inductively coupled plasma-mass spectrometry (ICP-MS). The resin showed very good adsorption for transition metals and rare-earth elements without any interference from alkali and alkaline-earth metals in an acidic media. In the proposed method, an aliquot of a 50-mL sample at $\mathrm{pH} 4$ was used. Metals adsorbed on the resin were eluted using $10 \mathrm{~mL}$ of $1 \mathrm{M}$ nitric and measured by ICP-MS. The method was evaluated by the analysis of NASS-5 seawater reference materials for trace metals. Good agreement was obtained for most metals, which indicates that by the proposed pretreatment using the synthesized resin, seawater samples can be favorably measured by ICP-MS.
\end{abstract}

(Received June 9, 2008; Accepted October 10, 2008; Published December 10, 2008)

Trace metals in aquatic systems have become a significant topic of concern in various fields associated with water quality, as well as a concern of the general public. Among several kinds of water samples, the determination of trace metals in seawater is the most interesting challenge in analytical chemistry, because of high concentrations of matrix and very low concentrations of analytes. Although inductively coupled plasma-mass spectrometry (ICP-MS) provides most accurate, sensitive and reliable detection for trace metals, its low tolerance of dissolved solids prohibits the direct analysis of trace metals in seawater samples by using this instrument. In the determination of trace metals in seawater by ICP-MS, the transition metals are interfered by polyatomic ions derived from alkali and alkalineearth metals, such as oxide and hydroxide. ${ }^{1-3}$ Therefore, preconcentration and matrix separation are required prior to the determination of trace metals by ICP-MS.

Sample pretreatment for the collection/concentration of analytes and the removal of matrix and interfering substances using chelating resin, such as commercially available iminodiacetate chelating resin, known as Chelex-100, ${ }^{4,5}$ Muromac A-1 ${ }^{6-9}$ and Toyopearl AF Chelate $650 \mathrm{M},{ }^{10-12}$ have been used for the determination of transition metals or rare-earth elements in seawater by ICP. The resins, however, can separate only some parts of alkali and alkaline-earth metals from analytes, and such sample matrix as $\mathrm{Na}^{+}, \mathrm{Ca}^{2+}, \mathrm{Mg}^{2+}$ and $\mathrm{Ba}^{2+}$ can remain with analytes and interfere with the determination of trace metals.

Several kinds of chelating resins have been proposed for the determination of transition metals or rare-earth elements in

† To whom correspondence should be addressed.

E-mail: motomizu@cc.okayama-u.ac.jp seawater samples. ${ }^{13-18}$ Since ICP-MS enables multi-element detection simultaneously, it is desirable to determine as many trace elements as possible, including transition metals and rareearth elements, for a comprehensive study of the distribution of trace elements in a marine environment.

Among the chelating reagents, ethylenediamine tetraacetic acid (EDTA) is one of the most stable chelating reagents, and can form chelates with a number of trace metal ions. Therefore, EDTA is a suitable chelating moiety for a multianalyte adsorption. Some chelating resins that possess the EDTA moiety have been synthesized using several kinds of polymer matrixes, such as cellulose, ${ }^{19}$ glycidyl methacrylate divinylbenzene, ${ }^{20}$ or chitosan. ${ }^{21-23}$ Nowadays, a chelating resin that possesses the EDTA moiety, Nobias Chelate-PA1, has been commercially available (Hitachi High Technologies, Tokyo, Japan). The resin has a good adsorption ability of transition and rare-earth metals, and can separate them from alkali and alkaline-earth metals. However, a high concentration of nitric acid was necessary to recover analytes from the resin, acetone was necessary for cleaning the resin, and furthermore resin particles were very small, which makes it difficult to use in a batchwise or a column pretreatment method, because of the slow flow rate.

We are mainly interested in a sorbent based on chitosan because of its unique combination of properties, like biodegradability, biocompatibility and bioactivity, in addition to attractive physical and mechanical properties. It is also reported that chitosan has the highest chelating ability compared to other natural polymers obtained from seafood wastes, activated sludge, and synthetic polymer poly(4-aminostyrene), which is used in commercial chelating ion-exchange resins. ${ }^{24}$ Since chitosan was soluble in acidic media, partial crosslinking of 
chitosan by di/polyfunctional reagents should be carried out to enable it to be used for metal complexation in acidic media. ${ }^{25}$

In this study, similar functional group with EDTA, ethylenediamine triacetic acid (EDTriA) was used as a moiety to make a new derivatization of a chitosan-based chelating resin, ethylenediamine- $N, N, N^{\prime}$-triacetate-type chitosan (EDTriA-type chitosan) resin. About 26 elements ( $\mathrm{Al}, \mathrm{Mn}, \mathrm{Co}, \mathrm{Ni}, \mathrm{Cu}, \mathrm{Ag}$, $\mathrm{Cd}, \mathrm{Pb}, \mathrm{Th}, \mathrm{U}, \mathrm{Y}$ and lanthanides) can be adsorbed quantitatively on the resin (more than 95\%), and can be separated from alkali and alkaline-earth metals in acidic media. Therefore, the resin can be favorably used for multi-element collection/preconcentration of trace metals and for removing the matrix in seawater before measuring trace metals by ICP-MS.

\section{Experimental}

\section{Reagents and chemicals}

Chitosan (deacetylated degree $80 \%$ ) used in this work was a flake type, purchased from Tokyo Kasei Co. Ltd. (Tokyo, Japan). All other reagents used for the synthesis of resin were of analytical reagent grade.

A multi-element stock standard solution (55 elements, $1 \mu \mathrm{g}$ $\mathrm{mL}^{-1}$ ) was prepared by diluting an analytical multi-element standard solution, XSTC-13, which contained $10 \mu \mathrm{g} \mathrm{mL}-1$ of metal ions ( $\mathrm{Li}, \mathrm{Be}, \mathrm{Na}, \mathrm{Mg}, \mathrm{Al}, \mathrm{K}, \mathrm{Ca}, \mathrm{V}, \mathrm{Cr}, \mathrm{Mn}, \mathrm{Fe}, \mathrm{Co}, \mathrm{Ni}$, $\mathrm{Cu}, \mathrm{Zn}, \mathrm{Ga}, \mathrm{As}, \mathrm{Se}, \mathrm{Rb}, \mathrm{Sr}, \mathrm{Ag}, \mathrm{Cd}$, In, Cs, Ba, Hg, Tl, Pb, Bi, Th, and U), an analytical multi-element standard solution, XSTC-1, containing $10 \mu \mathrm{g} \mathrm{mL}^{-1}$ of metal ions (Ce, Dy, Er, Eu, Gd, Ho, $\mathrm{La}, \mathrm{Lu}, \mathrm{Nd}, \mathrm{Pr}, \mathrm{Sm}, \mathrm{Sc}, \mathrm{Tb}, \mathrm{Tm}, \mathrm{Yb}$, and $\mathrm{Y}$ ) purchased from Spex CertiPrep Inc. (Metuchen, NJ), and standard solutions for

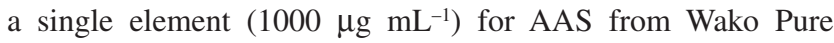
Chemicals Industries, Ltd. (Osaka, Japan) (Zr, Pd, Sn, Sb, Te, $\mathrm{Hf}, \mathrm{Pt}$, and $\mathrm{Au}$ ) in $0.1 \mathrm{M}$ of a nitric acid solution. Working standard solutions were prepared daily by diluting the stock standard solution with nitric acid. All dilution procedures were performed by weight.

Ultra-pure grade nitric acid $\left(60 \%\right.$, density of $1.38 \mathrm{~g} \mathrm{~mL}^{-1}$; Kanto Chemicals, Tokyo, Japan), was used and diluted with an ultra-pure water to give a $0.01 \mathrm{M}$, or a $1 \mathrm{M}$ solution.

An internal standard solution was prepared by diluting a rhodium and a germanium standard solution for AAS from Wako Pure Chemical Industries, Ltd. (Japan) in $1 \mathrm{M}$ nitric acid. These solutions were used to compensate for any instrumental drift or physical interferences. An internal standard was added to blanks, samples, and standards in a similar manner, so that dilution effects resulting from the addition could be disregarded..$^{26,27}$ An appropriate volume of an internal standard was added to reach a concentration of $10 \mathrm{ng} \mathrm{mL}^{-1}$ in the final solution.

A stock solution of $4 \mathrm{M}$ ammonium acetate buffer solution was prepared by mixing appropriate amounts of concentrated acetic acid and a concentrated ammonia solution, and diluted with ultra-pure water. Both the acetic acid and the ammonia solution were of electronic industrial reagent grade from Kanto Chemicals (Japan). Buffer solutions of 0.2 and $0.5 \mathrm{M}$ ammonium acetate were prepared by diluting a $4 \mathrm{M}$ ammonium acetate stock standard solution and adjusting to $\mathrm{pH} 3-9$ with small amounts of concentrated ammonia or acetic acid.

The ultrapure water $\left(18.3 \mathrm{M} \Omega \mathrm{cm}^{-1}\right.$ resistivity) was prepared by an Elix-3/Milli-Q element system, Nihon Millipore (Tokyo, Japan).

An artificial seawater sample containing $0.47 \mathrm{M} \mathrm{Na}^{+}, 0.05 \mathrm{M}$ $\mathrm{Mg}^{2+}, 0.01 \mathrm{M} \mathrm{Ca}^{2+}, 0.01 \mathrm{M} \mathrm{K}^{+}, 0.55 \mathrm{M} \mathrm{Cl}^{-}$and $0.03 \mathrm{M} \mathrm{SO}_{4}{ }^{2-}$ was prepared by mixing appropriate amounts of salts of calcium
Table 1 ICP-MS operating conditions

\begin{tabular}{ll}
\hline \multicolumn{1}{c}{ ICP-MS } & Model Seiko SPQ $8000 \mathrm{H}$ quadrupole type \\
\hline Plasma condition & \\
Forward power & $1.1 \mathrm{~kW}$ \\
Reflected power & $<5 \mathrm{~W}$ \\
Plasma gas & $\mathrm{Ar} 15 \mathrm{~L} \mathrm{~min}^{-1}$ \\
Carrier gas & $\mathrm{Ar} 0.45 \mathrm{~L} \mathrm{~min}^{-1}$ \\
Auxiliary gas & $\mathrm{Ar} 0.50 \mathrm{~L} \mathrm{~min}^{-1}$ \\
Sample uptake rate & $1.0 \mathrm{ml} \mathrm{min}^{-1}$ \\
Interface condition & $10 \mathrm{~mm} \mathrm{from} \mathrm{load} \mathrm{coil}$ \\
Sampling depth & Copper $1.1 \mathrm{~mm}$ i.d. \\
Sampling cone & Copper $0.35 \mathrm{~mm}$ i.d. \\
Skimmer cone & \\
\hline
\end{tabular}

chloride, sodium sulfate, potassium chloride, sodium chloride and magnesium chloride in $0.01 \mathrm{M}$ nitric acid solution. ${ }^{28,29}$ All of the reagents were of analytical reagent grade from Wako Pure Chemical Industries, Ltd. (Japan).

Seawater samples were collected at Shibukawa seashore (Tamano City), Ushimado seashore (Setouchi City), and at Okayama Port (Okayama City). The sample solutions were acidified to $\mathrm{pH}<2$ by adding concentrated nitric acid and filtered through a $0.45-\mu \mathrm{m}$ membrane filter from Toyo Roshi Kaisha, Ltd. (Tokyo, Japan) before storing. ${ }^{4}$ The $\mathrm{pH}$ of $50 \mathrm{~mL}$ sample solutions was adjusted to 4 just before a column pretreatment by adding small amounts of a concentrated ammonia solution.

NASS-5 seawater reference material for trace metals was purchased from Chemical Metrology, Institute for National Measurement Standards, National Research Council of Canada (Ontario, Canada).

\section{Apparatus}

Measurements were carried out on an ICP-MS system, a Model SPQ8000H System, Seiko Instruments Co. (Tokyo, Japan). The operating conditions are listed in Table 1. Infrared spectra $\left(4000-400 \mathrm{~cm}^{-1}\right)$ were recorded on a Jasco FT/IR-4100, Jasco International Co. Ltd. (Tokyo, Japan).

\section{Procedure for synthesis of EDTriA-type chitosan resin}

EDTriA-type chitosan resin was synthesized in three steps, as shown in Fig. 1.

Step 1: synthesis of cross-linked chitosan.

In this step, chitosan (flake type, $\phi 100-300 \mu \mathrm{m}$ ) was crosslinked using ethylene glycol diglycidyl ether (EDGE), as described in previous work. ${ }^{25}$ This cross-linked chitosan was used to make the derivative resin.

Step 2: synthesis of ethylenediamine-type chitosan.

The cross-linked chitosan was reacted with chloromethyloxyrane (as a coupling arm) before being coupled with ethylenediamine to perform ethylenediamine-type chitosan. The procedure was described in a previous paper. ${ }^{30}$

Step 3: synthesis of EDTriA-type chitosan.

The EDTriA-type chitosan resin was synthesized by modifying ethylenediamine-type chitosan ${ }^{30}$ using bromoacetic acid, as follows. Bromoacetic acid, $3.9 \mathrm{~g}(28 \mathrm{mmol})$ was dissolved in $16 \mathrm{~mL}$ of ice-cold water. To this solution, under cooling in an ice-water bath, was added $2.5 \mathrm{M} \mathrm{NaOH}$ until the $\mathrm{pH}$ reached 12. Three grams of ethylenediamine-type chitosan resin $(7 \mathrm{mmol})$ was suspended in $20 \mathrm{~mL}$ of water and mixed with a solution of bromoacetic acid, and then warmed to 40 $45^{\circ} \mathrm{C}$ in a water bath. The $\mathrm{pH}$ was maintained at 12 by adding a small amount of $2.5 \mathrm{M} \mathrm{NaOH}$ for $6-7 \mathrm{~h}$. The solid product 
Step 1: synthesis of cross-linked chitosan

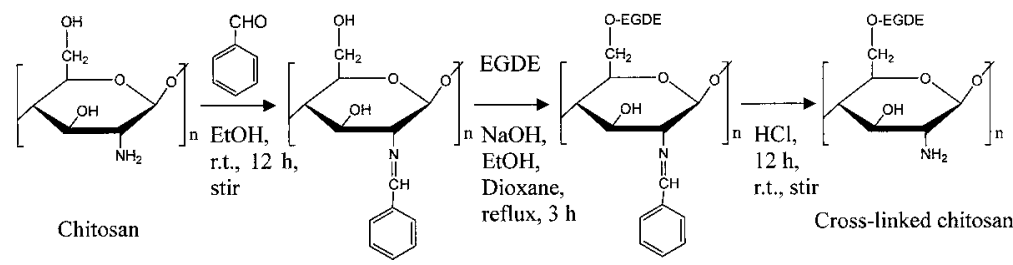

Cross-linking: Ethylene Glycol Diglycidyl Ether (EGDE)
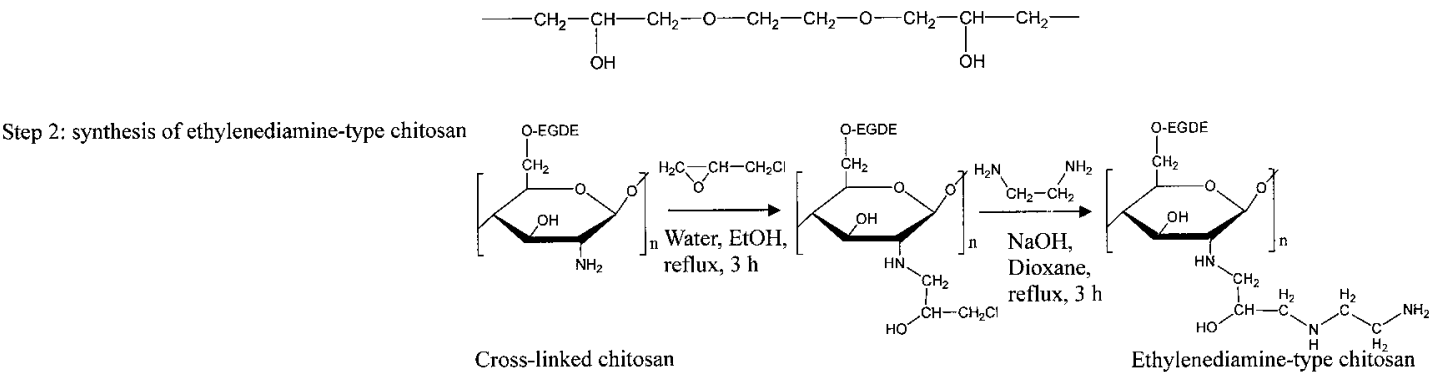

Step 3: synthesis of EDTriA-type chitosan

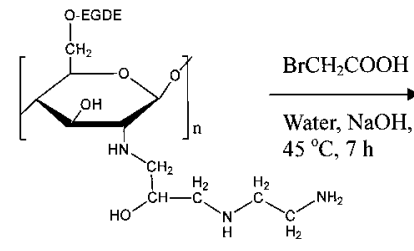

Ethylenediamine-type chitosan

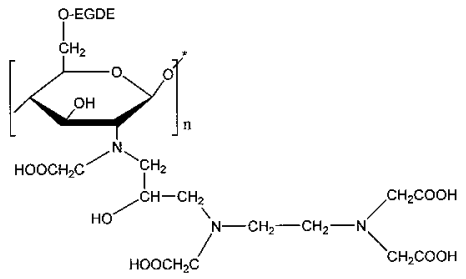

EDTriA-type chitosan

Fig. 1 Reaction scheme for the synthesis of ethylenediamine- $N, N, N^{\prime}$-triacetate-type chitosan (EDTriA-type chitosan) resin.

(EDTriA-type chitosan resin) was filtered on a filter paper, and then washed three times with ethanol and water. By this reaction, acetyl groups from bromoacetatic acid could bind with the amino groups ${ }^{31}$ of the ethylenediamine-type chitosan.

\section{Mini-column procedure for collection and concentration of trace metals}

Before using, the EDTriA-type chitosan resin was cleaned to remove any metal impurities in the resin. Ten milliliters of wet resin were transferred to a plastic beaker; to it, $50 \mathrm{~mL}$ of $2 \mathrm{M}$ nitric acid was added. The mixture was carefully stirred at low speed for $6 \mathrm{~h}$. The aqueous solution was decanted, and the resin was rinsed with ultrapure water until the $\mathrm{pH}$ of the effluent was the same as that of ultrapure water.

Approximately $1 \mathrm{~mL}$ of wet resin was packed in a polypropylene Muromac ${ }^{\circledR}$ mini column, $5 \mathrm{~mm}$ i.d. $\times 50 \mathrm{~mm}$, Muromachi Kagaku Kogyo Kaisha, Ltd. (Tokyo, Japan). Through the column were passed $10 \mathrm{~mL}$ of $1 \mathrm{M}$ nitric acid, 10 $\mathrm{mL}$ of ultrapure water for washing, and $5 \mathrm{~mL}$ of a $0.5 \mathrm{M}$ ammonium acetate buffer solution at $\mathrm{pH} 4$ for column conditioning. After pretreatment of the column, $50 \mathrm{~mL}$ of sample solutions at $\mathrm{pH} 4$ were passed through the column, and then $5 \mathrm{~mL}$ of a $0.2 \mathrm{M}$ ammonium acetate buffer solution at $\mathrm{pH} 4$ and $5 \mathrm{~mL}$ of ultrapure water were passed for eliminating the matrix. Finally, $10 \mathrm{~mL}$ of $1 \mathrm{M}$ nitric acid was passed through the column for recovering metals adsorbed on the resin. Therefore 5-fold preconcentration was achieved. The eluent was collected in a pre-cleaned screw-capped polypropylene bottle, and then analyzed by ICP-MS after adding Rh and Ge as internal standards.

For examining the adsorption behavior of the resin, 9 mini columns containing the EDTriA-type chitosan resin were used; each column was used for a different $\mathrm{pH}$. Nitric acid for $\mathrm{pH} 1-2$ and $0.5 \mathrm{M}$ ammonium acetate buffer for $3<\mathrm{pH}<9$ were used for column conditioning, while a lower concentration of a buffer solution, $0.2 \mathrm{M}$ ammonium acetate buffer, were used to remove the sample matrix. The procedure was carried out in the same manner as describe earlier. For the sample, $10 \mathrm{~mL}$ of a solution containing $5 \mathrm{ng} \mathrm{mL}^{-1}$ of each element, the $\mathrm{pHs}$ of which were adjusted to appropriate values, was used. All of the effluents were collected and analyzed by ICP-MS after adding Rh and Ge as internal standards.

Throughout the column pretreatment, the flow rate (by gravity) of the rinsing solutions, samples, and the eluents was about $2 \mathrm{~mL} \mathrm{~min}^{-1}$. The time required for the whole column pretreatment, for $50 \mathrm{~mL}$ of sample solutions, was $48 \mathrm{~min}$.

\section{Acid digestion prior to the analysis of $\mathrm{Al}, \mathrm{Mn}, \mathrm{Co}$, and $\mathrm{Ni}$}

For the determination of $\mathrm{Al}, \mathrm{Mn}, \mathrm{Co}$, and $\mathrm{Ni}$, a seawater sample should be digested prior to analysis. To $50 \mathrm{~mL}$ of a seawater sample placed in a PTFE beaker, $1 \mathrm{~mL}$ of $(1+1)$ nitric acid and $0.5 \mathrm{~mL}$ of $(1+1)$ hydrochloric acid were added. The beaker was placed in an evaporation chamber for solution evaporation at a temperature of approximately, but not higher than at $85^{\circ} \mathrm{C}$. The volume of the sample aliquot was reduced to about $3 \mathrm{~mL}$ by gentle heating at $85^{\circ} \mathrm{C}$, and refluxed for $30 \mathrm{~min}$ by increasing the temperature at $120^{\circ} \mathrm{C}$, and then evaporated to dryness. ${ }^{32}$ The evaporation chamber was covered with a clear polyvinyl sheet to prevent samples from contamination. The residue in the beaker was redissolved with $10 \mathrm{~mL}$ of $0.01 \mathrm{M}$ nitric acid and adjusted to $\mathrm{pH} 4$ by adding small amounts of a concentrated ammonium solution before passing through a column that contained EDTriA-type chitosan resin. Elements adsorb on the resin were eluted by $10 \mathrm{~mL} 1 \mathrm{M}$ nitric acid and 
measured by ICP-MS.

Since the concentrations of $\mathrm{Al}$ and $\mathrm{Mn}$ in real seawater samples were sufficiently high to be detected by ICP-MS without any preconcentration, for the determination of $\mathrm{Al}$ and $\mathrm{Mn}, 10 \mathrm{~mL}$ of samples was used. To a $10-\mathrm{mL}$ seawater sample placed in a PTFE beaker, $0.2 \mathrm{~mL}$ of $(1+1)$ nitric acid and 0.1 $\mathrm{mL}$ of $(1+1)$ hydrochloric acid were added, and then evaporated in the same manner as in the previous procedure.

\section{Results and Discussion}

\section{Characteristics of the EDTriA-type chitosan resin}

Infrared spectra $\left(4000-400 \mathrm{~cm}^{-1}\right)$ were recorded (Fig. 2). In the fingerprint region $\left(1500-500 \mathrm{~cm}^{-1}\right)$, the spectrum of EDTriA-type chitosan resin was totally different from that of the cross-linked chitosan and the ethylenediamine-type chitosan.

New bands appeared when a carboxymethyl group connected to the ethylenediamine-type chitosan resin. The band at 680 $\mathrm{cm}^{-1}$ in Fig. 2C confirmed a $\mathrm{O}-\mathrm{C}=\mathrm{O}$ bend of the carboxylate group. Other bands at 1100 and $1300 \mathrm{~cm}^{-1}$ confirmed $\mathrm{C}-\mathrm{O}$ stretch, and at $2650-2750 \mathrm{~cm}^{-1}$ confirmed $\mathrm{O}-\mathrm{H}$ stretch of carboxylic acid. ${ }^{33}$ The band at $1550 \mathrm{~cm}^{-1}$, which confirmed a N-H bend of $1^{\circ}$ amine of the cross-linked chitosan and ethylenediaminetype chitosan (Figs. 2A and 2B), disappeared in the spectrum of EDTriA-type chitosan (Fig. 2C), which means that almost all of the free amine was converted to the aminoacetate.

Adsorption behavior of elements on EDTriA-type chitosan resin The adsorption behavior of elements on EDTriA-type chitosan resin was examined using $10 \mathrm{~mL}$ of $5 \mathrm{ng} \mathrm{mL}^{-1}$ standard metal solutions. As shown in Fig. 3, the EDTriA-type chitosan resin has very good adsorption ability for transition metals and rareearth elements from $\mathrm{pH} 3$ to 7 . The resin did not adsorb both alkali and alkaline-earth metals in acidic media $(\mathrm{pH}<6)$. Increasing the $\mathrm{pH}$ could increase the adsorption of alkaline-earth metal on the resin. Therefore, $\mathrm{pH} 4$ was selected for further investigation. All elements that could adsorb on the resin were found to be recovered at greater than $95 \%$ with $10 \mathrm{~mL}$ of $1 \mathrm{M}$ nitric acid.

Compared with the ethylenediamine-type chitosan resin which can selectively adsorb silver from $\mathrm{pH} 1$ to 8 , as reported in a previous paper, ${ }^{30}$ the proposed resin, synthesized by introducing an acetyl group to the amino group of the ethylenediamine-type chitosan, EDTriA-type chitosan resin, has a totally different adsorption behavior. There are 26 elements that can be adsorbed with greater than $95 \%$ on the EDTriA-type chitosan resin, including silver. This means that introducing the acetyl group into the resin not only gives additional chelating rings, but can also change the resin character. Similarly to the chelate in aqueous solutions, the selectivity of suitable functional groups fixed into the polymer had also been explained on the basis of the concept of strong and weak acids and bases ${ }^{34}$ or hard and soft ligands. ${ }^{35}$ Transforming donor atoms $(\mathrm{N}, \mathrm{N})$ of ethylenediamine-type chitosan to donor atoms $(\mathrm{O}, \mathrm{N})$ of EDTriA-type chitosan could increase the adsorption ability of the EDTriA-type chitosan toward such "borderline" cations as transition metals.

\section{Adsorption capacity of EDTriA-type chitosan resin}

Though a number of metals can adsorb on the resin, $\mathrm{Cu}(\mathrm{II})$ was selected for examining the adsorption capacity of the EDTriA-type chitosan resin. One milliliter of the wet EDTriAtype chitosan resin was equilibrated in $100 \mathrm{~mL}$ of $1.4 \mathrm{mM}$ $\mathrm{Cu}$ (II) ion at $\mathrm{pH}$ 4. The adsorption capacity of $\mathrm{Cu}$ (II) on the EDTriA-type chitosan resin was $0.043 \mathrm{mmol} \mathrm{mL}^{-1}$ of the resin

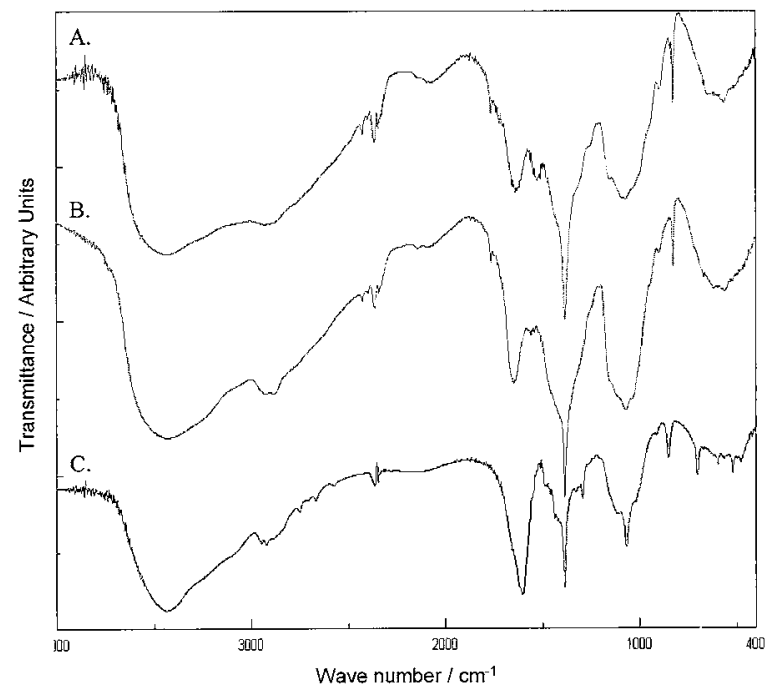

Fig. 2 FTIR spectra: A, cross-linked chitosan; B, ethylenediaminetype chitosan; C, EDTriA-type chitosan.

or $0.12 \mathrm{mmol} \mathrm{g}^{-1}$ of the resin, and the $t_{1 / 2}$ of $\mathrm{Cu}$ (II) adsorbed was less than $10 \mathrm{~min}$.

\section{Collection efficiency in column pretreatment}

The collection efficiencies of metals on a column packed with EDTriA-type chitosan resin was studied by comparing the slopes of the calibration graph, which were obtained by column pretreatments and direct measurements. In a direct measurement, the standard solution in $1 \mathrm{M} \mathrm{HNO}_{3}$ was measured directly by ICP-MS, without passing it through the column. The result is given in Table 2 .

There were 26 metals that could be collected with greater than 95\% efficiency on a column packed with EDTriA-type chitosan resin when $10 \mathrm{~mL}$ of the sample was used, as shown in Fig. 3. However, when $50 \mathrm{~mL}$ of the sample was used, as given in Table 2, the collection of $\mathrm{Al}$ and $\mathrm{Mn}$ decreased to about $90 \%$. Since the concentrations of $\mathrm{Al}$ and $\mathrm{Mn}$ in real samples were high enough to be detected without any preconcentration, the preconcentration procedure was not performed. For determining $\mathrm{Al}$ and $\mathrm{Mn}$, mini column procedure was used only for removing the seawater matrix. For Ag, a calibration graph obtained by the column pretreatment was not linear; the chelation of $\mathrm{Ag}$ with the resin seemed to be weak.

Effect of major cations in the seawater matrix on the determination of trace metals

Interference arising from the salt matrix present in the samples could vary with the sample salinity, and therefore could not be corrected by using a blank solution. Since major cations present in seawater were alkali and alkaline-earth metals $(\mathrm{Mg}, \mathrm{Ca}, \mathrm{Na}$, and $\mathrm{K}$ ), and both alkali and alkaline-earth metals in acidic media did not adsorb on the EDTriA-type chitosan resin, and could be passed to waste while the trace metals were retained on the resin, trace metals could be separated from the major cations in the seawater matrix. This means that the effect of major cations could be eliminated by a column pretreatment using EDTriAtype chitosan resin.

Effect of anions in the seawater matrix on the determination of trace metals

The effect of major anions, chloride and sulfate, in the sample matrix was studied by comparing the slopes of the calibration 


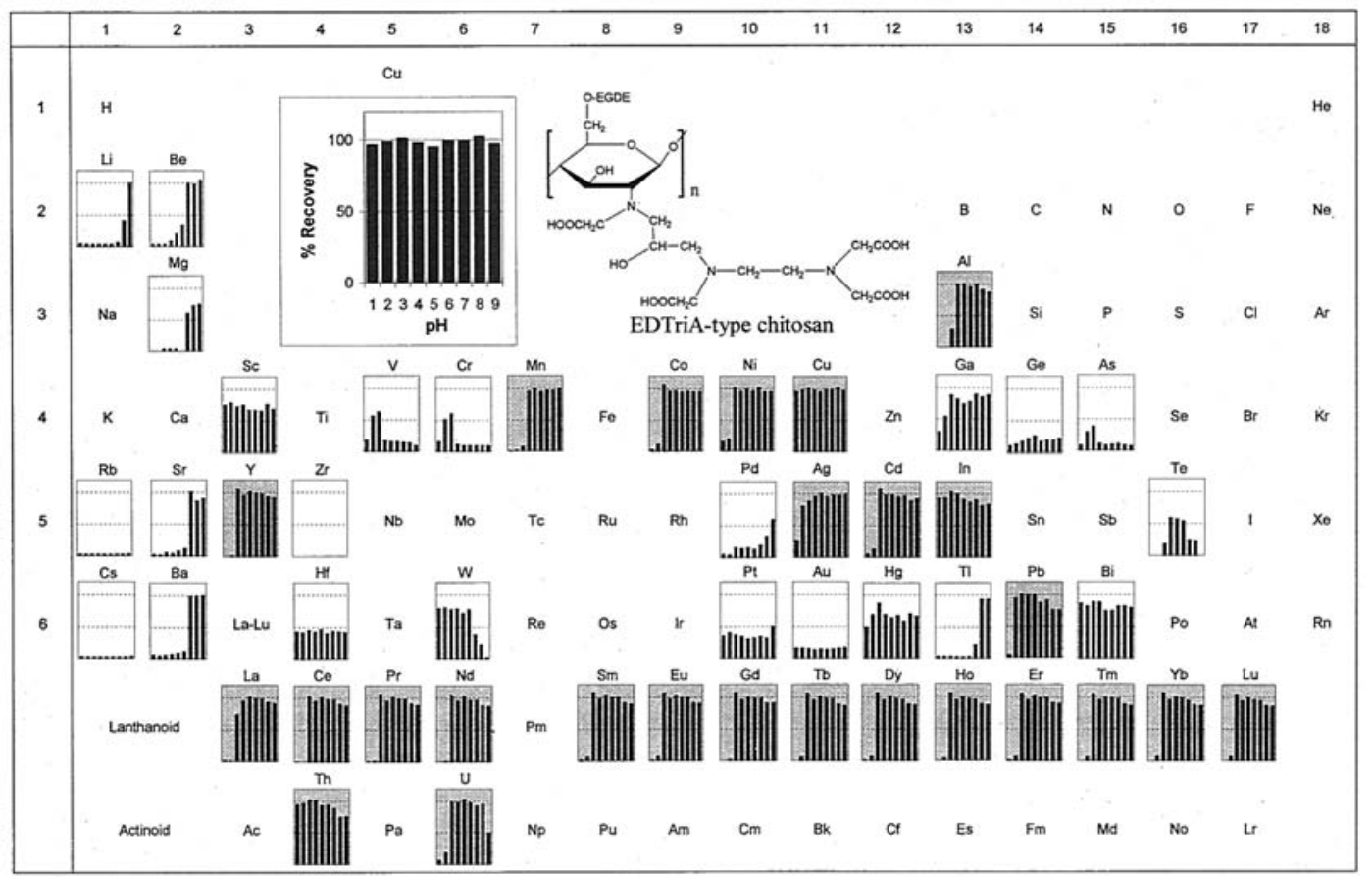

Fig. 3 Adsorption behavior of EDTriA-type chitosan for metals at various $\mathrm{pH}$ values. Sample volume, $10 \mathrm{~mL}$; concentration of each metal, $5 \mathrm{ng} \mathrm{mL}^{-1}$; eluent, $10 \mathrm{~mL}$ of $1 \mathrm{M}$ nitric acid.

Table 2 Slopes ratio $(r)$ of the calibration graph obtained by a column pretreatment to that obtained by a direct measurement

\begin{tabular}{|c|c|c|c|}
\hline \multirow[t]{2}{*}{ Element } & \multirow{2}{*}{$\begin{array}{l}\text { Slope ratio }(r), \\
\mathrm{HNO}_{3}(\text { column }) / \\
\mathrm{HNO}_{3} \text { (direct) }\end{array}$} & \multicolumn{2}{|c|}{$\begin{array}{c}\text { Slope ratio }(r), \\
\text { artificial seawater } \\
(\text { column }) / \mathrm{HNO}_{3}(\text { direct })\end{array}$} \\
\hline & & $\begin{array}{c}\text { Without acid } \\
\text { digestion }\end{array}$ & $\begin{array}{l}\text { With acid } \\
\text { digestion }\end{array}$ \\
\hline $\mathrm{Al}$ & 0.8948 & $0.8149^{\mathrm{a}}$ & $0.9317^{\mathrm{a}}$ \\
\hline $\mathrm{Mn}$ & 0.9063 & $0.7530^{\mathrm{a}}$ & $0.9856^{a}$ \\
\hline Co & 1.0053 & 0.9795 & \\
\hline $\mathrm{Ni}$ & 0.9471 & 0.9898 & \\
\hline $\mathrm{Cu}$ & 0.9600 & 0.9123 & \\
\hline $\mathrm{Cd}$ & 0.9598 & 0.9205 & \\
\hline In & 1.0007 & 0.9810 & \\
\hline $\mathrm{Pb}$ & 0.9359 & 0.9731 & \\
\hline Th & 0.9381 & 0.9108 & \\
\hline U & 1.0192 & 1.0207 & \\
\hline $\mathrm{Y}$ & 0.9756 & 0.9981 & \\
\hline $\mathrm{La}$ & 0.9992 & 0.9739 & \\
\hline $\mathrm{Ce}$ & 0.9870 & 1.0389 & \\
\hline $\operatorname{Pr}$ & 0.9827 & 0.9921 & \\
\hline $\mathrm{Nd}$ & 1.0420 & 0.9730 & \\
\hline $\mathrm{Sm}$ & 0.9854 & 0.9066 & \\
\hline $\mathrm{Eu}$ & 0.9733 & 1.0318 & \\
\hline $\mathrm{Gd}$ & 0.9579 & 1.0530 & \\
\hline $\mathrm{Tb}$ & 0.9896 & 0.9709 & \\
\hline Dy & 1.0444 & 1.0124 & \\
\hline Ho & 0.9790 & 0.9988 & \\
\hline Er & 0.8936 & 0.9779 & \\
\hline $\mathrm{Tm}$ & 1.0027 & 0.9855 & \\
\hline $\mathrm{Yb}$ & 1.0171 & 1.0780 & \\
\hline Lu & 0.9980 & 1.0186 & \\
\hline
\end{tabular}

a. Sample volume, $10 \mathrm{~mL}$; eluent, $10 \mathrm{~mL}$ (1-fold preconcentration).

graphs for artificial seawater samples, which could be obtained by a column pretreatment and calibration graphs for standard samples in $1 \mathrm{M} \mathrm{HNO}_{3}$, which could be obtained by direct measurements. The results given in Table 2 indicate that both of the calibration graphs for metals are in good agreement with one another (slope ratio was about 1), except for $\mathrm{Al}$ and $\mathrm{Mn}$. This means that the major anions in the seawater matrix did not interfere with the collection of trace metals on the column that contained EDTriA-type chitosan resin, except for $\mathrm{Al}$ and $\mathrm{Mn}$.

Aluminum forms stable complexes with sulfate and electronrich species, such as fluoride and chloride, which make it difficult to bind with the resin. Additionally, $\mathrm{Al}$ may be bound to organic and inorganic ligands as well as to particulate matter. ${ }^{36}$ From thermodynamic considerations, $\mathrm{MnO}_{2}$ is expected to be the stable form of $\mathrm{Mn}$ in seawater. However, seawater contains a significant quantity of dissolved $\mathrm{Mn}(\mathrm{II})$, which is slowly oxidized. Investigations of the oxidation of $\mathrm{Mn}$ (II) have shown that the process is autocatalytic, and depends on the reaction conditions. . $^{46}$ Only $\mathrm{Mn}$ (II) can form a stable chelate with EDTriA-type chitosan resin.

To solve the problem, before passing through the column, an artificial seawater samples was spiked with several concentrations of $\mathrm{Al}$ and $\mathrm{Mn}$, and was then digested. ${ }^{32}$ From the result shown in Table 2, the slope ratio of the calibration graphs for metals in the digested artificial seawater sample and those in the standard samples were increased to 0.93 and 0.99 for $\mathrm{Al}$ and $\mathrm{Mn}$, respectively. This means that by digestion using $\mathrm{HNO}_{3}$ and $\mathrm{HCl}$, all binding of $\mathrm{Al}$ with other compound could be completely destroyed and all $\mathrm{Mn}$ was reduced to $\mathrm{Mn}$ (II); therefore, $\mathrm{Al}$ and Mn could be collected completely on the resin.

Effect of other compounds in the seawater matrix on the determination of trace metals

Since artificial seawater was made by mixing only major cations and anions, ${ }^{28,29}$ real seawater samples have to be used to study the effect of other compounds that exist in seawater samples, such as natural or anthropogenic ligands. In this study, the seawater sample used was collected at the Shibukawa seashore, Tamano City, Okayama Prefecture. Shibukawa seawater was digested, ${ }^{32}$ and the analytical results from both sample preparation methods, the digested and the undigested procedure, were compared. As shown in Table 3, without acid digestion, only $50-80 \%$ of $\mathrm{Al}, \mathrm{Mn}, \mathrm{Co}$, and $\mathrm{Ni}$ were collected 
Table 3 Result obtained for trace metals in Shibukawa seawater without and with acid digestion

\begin{tabular}{ccc}
\hline Element & $\begin{array}{c}\text { Without acid digestion/ } \\
\text { ng mL }\end{array}$ & $\begin{array}{c}\text { With acid digestion } \\
\text { b/ } \\
\text { ng mL }\end{array}$ \\
\hline $\mathrm{Al}^{\mathrm{a}}$ & 13 & 27 \\
$\mathrm{Mn}^{\mathrm{a}}$ & 7.2 & 10.0 \\
$\mathrm{Co}$ & 0.069 & 0.087 \\
$\mathrm{Ni}$ & 0.92 & 1.35 \\
$\mathrm{Cu}$ & 2.6 & 2.4 \\
$\mathrm{Cd}$ & 0.17 & 0.17 \\
$\mathrm{In}$ & 0.0012 & 0.0011 \\
$\mathrm{~Pb}$ & 0.22 & 0.20 \\
$\mathrm{Th}$ & 0.0016 & 0.0016 \\
$\mathrm{U}$ & 2.6 & 2.5 \\
$\mathrm{Y}$ & 0.070 & 0.066 \\
$\mathrm{La}$ & 0.058 & 0.056 \\
$\mathrm{Ce}$ & 0.091 & 0.087 \\
$\mathrm{Pr}$ & 0.011 & 0.011 \\
$\mathrm{Nd}$ & 0.043 & 0.041 \\
$\mathrm{Sm}$ & 0.0077 & 0.0071 \\
$\mathrm{Eu}$ & 0.00084 & 0.00076 \\
$\mathrm{Gd}$ & 0.0107 & 0.0097 \\
$\mathrm{~Tb}$ & 0.0016 & 0.0015 \\
$\mathrm{Dy}$ & 0.010 & 0.0090 \\
$\mathrm{Ho}$ & 0.0021 & 0.0021 \\
$\mathrm{Er}$ & 0.0074 & 0.0065 \\
$\mathrm{Tm}$ & 0.00049 & 0.00044 \\
$\mathrm{Yb}$ & 0.0069 & 0.0068 \\
$\mathrm{Lu}$ & 0.00099 & 0.00088 \\
\hline
\end{tabular}

a. Sample volume, $10 \mathrm{~mL}$; eluent, $10 \mathrm{~mL}$ (1-fold preconcentration). b. Before column pretreatment, samples were digested using $\mathrm{HNO}_{3}$ and $\mathrm{HCl}$, based on EPA Method 200.8. ${ }^{32}$

on the resin, while for other metals no significant differences in the signal were obtained between undigested samples and the digested one.

In aqueous solutions Co exists mainly in the II oxidation state, but in some complexes $\mathrm{Co}$ (II) is readily oxidizable to $\mathrm{Co}(\mathrm{III})$. In certain circumstances, anthropogenic $\mathrm{Co}(\mathrm{III})$ picolinate, and to a lesser extent, naturally occurring cobalamine may also be present. ${ }^{36,37}$ Some complex species are sufficiently stable to persist in the environment for considerable periods of time, and thus influence the adsorption behavior of $\mathrm{Co}$ on a column containing EDTriA-type chitosan resin.

In natural water the dissolved forms of $\mathrm{Ni}$ can include the hydrated $\mathrm{Ni}^{2+}$ cation, complexes with inorganic ligands, such as chloro- and carbonato-complexes, or with various anthropogenic and natural ligands, such as terrestrial humic substances, or phytoplankton metabolites. ${ }^{36,38}$ These ligands compete with EDTriA-type chitosan resin to form stable complexes with $\mathrm{Ni}$.

As shown in Table 2, the collection of Co and $\mathrm{Ni}$ in artificial seawater on a column containing EDTriA-type chitosan resin was higher than $98 \%$. This means that the lower adsorption ability of $\mathrm{Co}$ and $\mathrm{Ni}$ in real seawater samples did not come from chloride and sulfate, but from other compounds or ligands. ${ }^{37,39}$ For complete adsorption of $\mathrm{Co}$ and $\mathrm{Ni}$ on the column contained EDTriA-type chitosan resin, before the column pretreatment, samples were digested to destruct all binding of $\mathrm{Co}$ and $\mathrm{Ni}$ with other compounds or ligands.

\section{Blank and detection limit}

Blank values, method detection limits (MDL), and instrument detection limits (IDL) are given in Table 4. An aliquot containing $50 \mathrm{~mL}$ of $0.01 \mathrm{M}$ nitric acid, the $\mathrm{pH}$ of which was adjusted to 4 just before a column pretreatment by adding small amounts of ammonia solution, was used as a blank solution and was processed in the same manner as the sample solutions. The average of 7 replicates was reported as blank values.

MDL was based on blank + 3SD, calculated as blank values, and three-times the standard deviation of the blank values. ${ }^{40,41}$ IDL is the concentration equivalent to the analyte signal, which
Table 4 Blank values, method detection limits (MDL), and instrument detection limits (IDL)

\begin{tabular}{cccc}
\hline Element & Blank $^{\mathrm{a}} / \mathrm{ng} \mathrm{mL}^{-1}$ & $\mathrm{MDL}^{\mathrm{b}} / \mathrm{ng} \mathrm{mL}^{-1}$ & $\mathrm{IDL}^{\mathrm{c}} / \mathrm{ng} \mathrm{mL}^{-1}$ \\
\hline${ }^{27} \mathrm{Al}$ & 0.040 & 0.070 & 0.16 \\
${ }^{55} \mathrm{Mn}$ & 0.040 & 0.10 & 0.24 \\
${ }^{59} \mathrm{Co}$ & 0.0011 & 0.0020 & 0.0078 \\
${ }^{60} \mathrm{Ni}$ & 0.047 & 0.054 & 0.031 \\
${ }^{63} \mathrm{Cu}$ & 0.052 & 0.12 & 0.63 \\
${ }^{111} \mathrm{Cd}$ & 0.0032 & 0.0057 & 0.017 \\
${ }^{115} \mathrm{In}$ & 0.00042 & 0.00059 & 0.0028 \\
${ }^{208} \mathrm{~Pb}$ & 0.00051 & 0.011 & 0.016 \\
${ }^{232} \mathrm{Th}$ & 0.0028 & 0.0080 & 0.011 \\
${ }^{238} \mathrm{U}$ & 0.0014 & 0.0046 & 0.0086 \\
${ }^{89} \mathrm{Y}$ & 0.00040 & 0.00096 & 0.0029 \\
${ }^{139} \mathrm{La}$ & 0.00039 & 0.0011 & 0.0024 \\
${ }^{140} \mathrm{Ce}$ & 0.0023 & 0.0056 & 0.015 \\
${ }^{141} \mathrm{Pr}$ & 0.00010 & 0.00035 & 0.0019 \\
${ }^{146} \mathrm{Nd}$ & 0.00028 & 0.0014 & 0.0078 \\
${ }^{147} \mathrm{Sm}$ & 0.00020 & 0.0010 & 0.0071 \\
${ }^{153} \mathrm{Eu}$ & 0.00011 & 0.00051 & 0.0025 \\
${ }^{157} \mathrm{Gd}$ & 0.00018 & 0.00081 & 0.0023 \\
${ }^{159} \mathrm{~Tb}$ & 0.00014 & 0.00021 & 0.0014 \\
${ }^{163} \mathrm{Dy}$ & 0.00013 & 0.00084 & 0.0045 \\
${ }^{165} \mathrm{Ho}$ & 0.000025 & 0.00015 & 0.0013 \\
${ }^{166} \mathrm{Er}$ & 0.00022 & 0.00083 & 0.0032 \\
${ }^{169} \mathrm{Tm}$ & 0.000030 & 0.00016 & 0.00098 \\
${ }^{172} \mathrm{Yb}$ & 0.000074 & 0.00045 & 0.0032 \\
${ }^{175} \mathrm{Lu}$ & 0.000015 & 0.00012 & 0.00095 \\
\hline
\end{tabular}

a. Sample blank, $50 \mathrm{~mL}$ of $0.01 \mathrm{M} \mathrm{HNO}_{3}$, $\mathrm{pH}$ was adjusted to 4 by adding small amount of ammonia; eluent, $10 \mathrm{~mL} 1 \mathrm{M} \mathrm{HNO}_{3}$. Data were averaged for 7 replicates.

b. Method detection limit, corresponding to blank + 3SD of sample blank with 5 -fold preconcentration, 7 replicates.

c. Instrument detection limit, corresponding to $3 \mathrm{SD}$ of $1 \mathrm{M} \mathrm{HNO}_{3}, 10$ measurements.

is equal to three-times the standard deviation of 10 replicate measurements of $1 \mathrm{M}$ nitric acid as the calibration blank signal (by direct measurement). ${ }^{32}$ From the obtained results, a 5-fold enrichment factor is sufficient to detect all trace metals in seawater samples.

\section{Accuracy and precision}

The accuracy and precision of the proposed column pretreatment method using the EDTriA-type chitosan resin were examined by analyzing the NASS- 5 seawater reference material for trace metals issued by the National Research Council of Canada (Ottawa, Ontario, Canada). Since there are no certified values for rare-earth elements, the results obtained in this work were compared with reference values reported by Willie et al. ${ }^{10}$ and Zhu et al. ${ }^{5}$ The sample $\mathrm{pH}$ was adjusted to 4 before a column pretreatment, and used without any acid digestion to prevent the metal ions from any loses or contamination. Therefore, the results of $\mathrm{Al}, \mathrm{Mn}, \mathrm{Ni}$ and $\mathrm{Co}$ obtained in this experiment are lower than those of the certified and reference values, as shown in Table 5. For other elements, the results were in good agreement with the certified and the reference values.

The obtained results indicate that the present method has good accuracy and precision, which are less than $10 \%$ of the relative standard deviation (RSD), and is applicable to the multi-element preconcentration and determination of trace metals in seawater samples.

\section{Application to the seawater samples}

The proposed method was successfully applied to the determination of trace metals in seawater samples from Okayama Prefecture, Japan, collected at Shibukawa seashore (Tamano City), Ushimado seashore (Setouchi City), and at Okayama Port (Okayama City). Only for the determination of $\mathrm{Al}, \mathrm{Mn}, \mathrm{Co}$, and $\mathrm{Ni}$, samples were digested using $\mathrm{HNO}_{3}$ and $\mathrm{HCl}$ before passing through a column containing EDTriA-type 
Table 5 Analytical results of trace metals in the NASS-5 seawater reference material for trace metals (ng L ${ }^{-1}$ )

\begin{tabular}{|c|c|c|c|c|}
\hline Element & This study ${ }^{\mathrm{a}}$ & Certified value & Reference value $1^{\mathrm{b}}$ & Reference value $2^{c}$ \\
\hline $\mathrm{Al}$ & $0.079 \pm 0.001$ & & & $0.11 \pm 0.02$ \\
\hline $\mathrm{Mn}$ & $0.51 \pm 0.0$ & $0.92 \pm 0.06$ & & $0.87 \pm 0.04$ \\
\hline $\mathrm{Co}$ & $0.0096 \pm 0.0009$ & $0.011 \pm 0.003$ & $0.015 \pm 0.001$ & $0.013 \pm 0.002$ \\
\hline $\mathrm{Ni}$ & $0.19 \pm 0.01$ & $0.25 \pm 0.03$ & $0.28 \pm 0.01$ & $0.24 \pm 0.01$ \\
\hline $\mathrm{Cu}$ & $0.31 \pm 0.02$ & $0.30 \pm 0.05$ & $0.26 \pm 0.01$ & $0.31 \pm 0.03$ \\
\hline $\mathrm{Cd}$ & $0.027 \pm 0.001$ & $0.023 \pm 0.003$ & $0.019 \pm 0.002$ & $0.03 \pm 0.00$ \\
\hline In & $0.0032 \pm 0.0003$ & & & \\
\hline $\mathrm{Pb}$ & $0.0059 \pm 0.0005$ & $0.008 \pm 0.005$ & $0.008 \pm 0.002$ & \\
\hline Th & $0.00081 \pm 0.00008$ & & & $0.0003 \pm 0.0000$ \\
\hline $\mathrm{U}$ & $2.8 \pm 0.1$ & 2.6 & $2.6 \pm 0.0$ & $2.66 \pm 0.05$ \\
\hline $\mathrm{Y}$ & $0.020 \pm 0.001$ & & & $0.02 \pm 0.00$ \\
\hline $\mathrm{La}$ & $0.014 \pm 0.001$ & & $0.013 \pm 0.001$ & $0.0111 \pm 0.0005$ \\
\hline $\mathrm{Ce}$ & $0.0047 \pm 0.0003$ & & $0.004 \pm 0.001$ & $0.0049 \pm 0.0003$ \\
\hline $\operatorname{Pr}$ & $0.0017 \pm 0.0001$ & & $0.0015 \pm 0.0002$ & $0.0019 \pm 0.0001$ \\
\hline $\mathrm{Nd}$ & $0.0076 \pm 0.0005$ & & $0.0099 \pm 0.0018$ & $0.0068 \pm 0.0005$ \\
\hline Sm & $0.0041 \pm 0.0002$ & & $0.004 \pm 0.000$ & $0.004 \pm 0.0003$ \\
\hline $\mathrm{Eu}$ & $0.00028 \pm 0.00002$ & & $0.00026 \pm 0.00005$ & $0.00040 \pm 0.00001$ \\
\hline $\mathrm{Gd}$ & $0.0017 \pm 0.0003$ & & $0.0015 \pm 0.0003$ & $0.0021 \pm 0.0001$ \\
\hline $\mathrm{Tb}$ & $0.00035 \pm 0.00002$ & & $0.00029 \pm 0.00005$ & $0.00024 \pm 0.00000$ \\
\hline Dy & $0.0018 \pm 0.0002$ & & $0.0016 \pm 0.0003$ & $0.0018 \pm 0.0001$ \\
\hline Ho & $0.00037 \pm 0.00004$ & & $0.00036 \pm 0.00005$ & $0.00044 \pm 0.00002$ \\
\hline $\mathrm{Er}$ & $0.0013 \pm 0.0001$ & & $0.0012 \pm 0.0002$ & $0.0013 \pm 0.0001$ \\
\hline $\mathrm{Tm}$ & $0.00016 \pm 0.00003$ & & $0.00015 \pm 0.00003$ & $0.00024 \pm 0.00000$ \\
\hline $\mathrm{Yb}$ & $0.0012 \pm 0.0001$ & & $0.0011 \pm 0.0002$ & $0.0013 \pm 0.0001$ \\
\hline $\mathrm{Lu}$ & $0.00017 \pm 0.00002$ & & $0.0002 \pm 0.0000$ & $0.00022 \pm 0.00002$ \\
\hline
\end{tabular}

a. Without acid digestion: sample volume, $50 \mathrm{~mL}$; eluent, $10 \mathrm{~mL} 1 \mathrm{M} \mathrm{HNO}_{3} ; 3$ replicates. b. Cited from Ref. 10. c. Cited from Ref. 5.

chitosan resin; $10 \mathrm{~mL}$ of samples were used for $\mathrm{Al}$ and $\mathrm{Mn}$ determination, while $50 \mathrm{~mL}$ of samples were used for $\mathrm{Co}$ and $\mathrm{Ni}$ determination. For other trace metals, $50 \mathrm{~mL}$ of samples were used without any acid digestion.

As shown in Table 6, the concentrations of trace metals in Ushimado seawater were generally higher than those in Okayama Port and Shibukawa seawater. Samples were spiked with several concentrations of metal ions; the spiked concentrations were as close as possible to the concentration found, and the recovery test was examined. The recovery results were in the range of $91 \%$ (Ho) to $110 \%$ (Tm).

\section{Conclusions}

A novel chelating resin using chitosan as a base material, EDTriA-type chitosan, was synthesized for the multi-element collection/concentration of trace metals. The resin had good adsorption ability for transition metals and rare-earth elements, and did not adsorb both alkali and alkaline-earth metals in acidic media. At pH 4, about 25 elements could be collected quantitatively and separated from alkali and alkaline-earth metals. All of the metals could be easily recovered from the resin using $1 \mathrm{M}$ nitric acid. The resin was also stable for several months of storage, and it was found that even after about 30-time use for the pretreatment of samples, the adsorption behavior was almost the same as the first adsorption behavior.

By a pretreatment using EDTriA-type chitosan resin, trace metals including rare-earth elements in seawater could be determined by ICP-MS with only 5-fold preconcentration.

\section{Acknowledgements}

This work was partially supported by a Grant-in-Aid for Scientific Research (B) (No. 19350038) from Japan Society for Promotion of Science (JSPS).

\section{References}

1. T. W. May and R. H. Wiedmeyer, At. Spectrosc., 1998, 19, 150.
2. E. H. Evans, J. Anal. At. Spectrom., 1993, 8, 1.

3. Y. Shao and G. Horlick, Appl. Spectrosc., 1991, 45, 143.

4. T. R. Crompton, "Analysis of Seawater", 1989, Butterworth, England.

5. Y. Zhu, A. Itoh, and H. Haraguchi, Bull. Chem. Soc. Jpn., 2005, 78, 107.

6. T. Sumida, T. Nakazato, H. Tao, M. Oshima, and S. Motomizu, Anal. Sci., 2006, 22, 1163.

7. E. Vassileva and N. Furuta, Spectrochim. Acta, Part B, 2003, 58, 1541.

8. P. H. Lin, K. S. K. Danadurai, and S. D. Huang, J. Anal. At. Spectrom., 2001, 16, 409.

9. S. Hirata, Y. Ishida, M. Aihara, K. Honda, and O. Shikino, Anal. Chim. Acta, 2001, 438, 205.

10. S. N. Willie and R. E. Sturgeon, Spectrochim. Acta, Part B, 2001, 56, 1707.

11. K. Ndung'u, R. P. Franks, K. W. Bruland, and A. R. Flegal, Anal. Chim. Acta, 2003, 481, 127.

12. S. N. Willie, J. W. H. Lam, L. Yang, and G. Tao, Anal. Chim. Acta, 2001, 447, 143.

13. J. W. McLaren, A. P. Mykytiuk, S. N. Willie, and S. S. Berman, Anal. Chem., 1985, 57, 2907.

14. A. Ramesh, K. R. Mohan, and K. Seshaiah, Talanta, 2002, 57, 243.

15. M. L. Wells and K. W. Bruland, Mar. Chem., 1998, 63, 145.

16. O. Vicente, A. Padro, L. Martinez, R. Olsina, and E. Marchevsky, Spectrochim. Acta, Part B, 1998, 53, 1281.

17. B. Wen, X. Shan, and S. Xu, Analyst, 1999, 124, 621.

18. B. K. Esser, A. Volpe, J. M. Kenneally, and D. K. Smith, Anal. Chem., 1994, 66, 1736.

19. F. E. Okieimen, D. E. Ogbeifun, G. N. Nwala, and C. A. Kumsah, Bull. Environ. Contam. Toxicol., 1985, 34, 866.

20. A. A. Atia, A. M. Donia, and K. Z. Elwakeel, Sep. Purif. Technol., 2005, 43, 43.

21. K. Inoue, K. Ohto, K. Yoshizuka, T. Yamaguchi, and T. Tanaka, Bull. Chem. Soc. Jpn., 1997, 70, 2443.

22. S. Nagib, K. Inoue, T. Yamaguchi, and T. Tamaru, Hydrometallurgy, 1999, 51, 73.

23. Y. Shimizu, S. Izumi, Y. Saito, and H. Yamaoka, J. Appl. Polym. Sci., 2004, 92, 2758.

24. A. J. Varma, S. V. Despande, and J. F. Kennedy, Carbohydr. Polym., 2004, 55, 77. 
Table 6 Analytical results of trace metals in real seawater samples

\begin{tabular}{|c|c|c|c|c|c|c|c|c|c|}
\hline \multirow[b]{2}{*}{ Element } & \multicolumn{3}{|c|}{ Seawater at Okayama Port ${ }^{\mathrm{a}}$} & \multicolumn{3}{|c|}{ Seawater at Shibukawa ${ }^{a}$} & \multicolumn{3}{|c|}{ Seawater at Ushimado ${ }^{a}$} \\
\hline & $\begin{array}{l}\text { Spiked/ } \\
\text { ng mL } \mathrm{mL}^{-1}\end{array}$ & Found/ng mL $\mathrm{m}^{-1}$ & $\begin{array}{c}\text { Recovery, } \\
\%\end{array}$ & $\begin{array}{l}\text { Spiked/ } \\
\text { ng mL } \mathrm{mL}^{-1}\end{array}$ & Found/ng mL $\mathrm{mL}^{-1}$ & $\begin{array}{c}\text { Recovery, } \\
\%\end{array}$ & $\begin{array}{l}\text { Spiked/ } \\
\text { ng mL-1 }\end{array}$ & Found/ng mL $\mathrm{mL}^{-1}$ & $\begin{array}{c}\text { Recovery, } \\
\%\end{array}$ \\
\hline $\mathrm{Al}^{\mathrm{b}, \mathrm{c}}$ & - & $23 \pm 2$ & - & - & $30 \pm 2$ & - & - & $60 \pm 3$ & - \\
\hline $\mathrm{Mn}^{\mathrm{b}, \mathrm{c}}$ & - & $8.0 \pm 0.6$ & - & - & $9.9 \pm 1.5$ & - & - & $11 \pm 2$ & - \\
\hline \multirow[t]{2}{*}{$\mathrm{Co}^{\mathrm{c}}$} & - & $0.082 \pm 0.005$ & & - & $0.087 \pm 0.004$ & & - & $0.096 \pm 0.003$ & \\
\hline & 0.05 & $0.128 \pm 0.003$ & $92.1 \pm 5.8$ & 0.05 & $0.135 \pm 0.003$ & $96.7 \pm 6.4$ & 0.05 & $0.145 \pm 0.003$ & $97.4 \pm 5.8$ \\
\hline \multirow[t]{2}{*}{$\mathrm{Ni}^{\mathrm{c}}$} & - & $1.1 \pm 0.0$ & & - & $1.3 \pm 0.1$ & & - & $1.1 \pm 0.1$ & \\
\hline & 1 & $2.0 \pm 0.1$ & $92.3 \pm 6.6$ & 1 & $2.4 \pm 0.0$ & $107.5 \pm 4.5$ & 1 & $2.1 \pm 0.9$ & $96.0 \pm 9.1$ \\
\hline \multirow[t]{2}{*}{$\mathrm{Cu}$} & - & $1.2 \pm 0.0$ & - & - & $2.6 \pm 0.0$ & - & - & $4.1 \pm 0.0$ & - \\
\hline & 0.3 & $1.5 \pm 0.0$ & $93.4 \pm 1.9$ & 0.3 & $2.9 \pm 0.2$ & $103.5 \pm 6.8$ & 0.3 & $4.4 \pm 0.1$ & $97.9 \pm 2.6$ \\
\hline \multirow[t]{2}{*}{$\mathrm{Cd}$} & - & $0.037 \pm 0.008$ & & - & $0.17 \pm 0.02$ & & - & $0.091 \pm 0.007$ & \\
\hline & 0.03 & $0.069 \pm 0.002$ & $108.1 \pm 3.0$ & 0.1 & $0.27 \pm 0.01$ & $101.2 \pm 5.7$ & 0.1 & $0.190 \pm 0.010$ & $99.0 \pm 8.4$ \\
\hline \multirow[t]{2}{*}{ In } & - & $0.0017 \pm 0.0003$ & & - & $0.0012 \pm 0.0001$ & & - & $0.00070 \pm 0.00016$ & \\
\hline & 0.03 & $0.0349 \pm 0.0029$ & $110.6 \pm 8.3$ & 0.03 & $0.0310 \pm 0.0007$ & $99.5 \pm 2.1$ & 0.03 & $0.0316 \pm 0.0019$ & $102.9 \pm 4.0$ \\
\hline \multirow[t]{2}{*}{$\mathrm{Pb}$} & - & $0.56 \pm 0.02$ & & - & $0.22 \pm 0.001$ & & - & $1.2 \pm 0.0$ & \\
\hline & 0.3 & $0.85 \pm 0.04$ & $97.1 \pm 4.8$ & 0.1 & $0.31 \pm 0.02$ & $91.7 \pm 4.8$ & 0.3 & $1.5 \pm 0.0$ & $98.9 \pm 0.1$ \\
\hline \multirow[t]{2}{*}{ Th } & - & $0.0030 \pm 0.0006$ & & - & $0.0016 \pm 0.0004$ & & - & $0.032 \pm 0.003$ & \\
\hline & 0.03 & $0.0320 \pm 0.0015$ & $96.7 \pm 4.7$ & 0.03 & $0.0334 \pm 0.0008$ & $106.1 \pm 2.3$ & 0.03 & $0.064 \pm 0.002$ & $107.8 \pm 3.5$ \\
\hline \multirow[t]{2}{*}{$\mathrm{U}$} & - & $0.77 \pm 0.02$ & & - & $2.6 \pm 0.1$ & & - & $2.4 \pm 0.1$ & \\
\hline & 0.03 & $1.06 \pm 0.01$ & $97.2 \pm 1.2$ & 0.3 & $2.9 \pm 0.1$ & $98.6 \pm 2.7$ & 0.3 & $2.7 \pm 0.1$ & $95.2 \pm 2.1$ \\
\hline \multirow[t]{2}{*}{$\mathrm{Y}$} & - & $0.078 \pm 0.001$ & & - & $0.070 \pm 0.003$ & & - & $0.12 \pm 0.01$ & \\
\hline & 0.03 & $0.107 \pm 0.001$ & $97.5 \pm 0.6$ & 0.03 & $0.102 \pm 0.001$ & $105.7 \pm 0.9$ & 0.03 & $0.15 \pm 0.00$ & $99.8 \pm 1.1$ \\
\hline \multirow[t]{2}{*}{$\mathrm{La}$} & - & $0.082 \pm 0.004$ & & - & $0.058 \pm 0.003$ & & - & $0.15 \pm 0.01$ & \\
\hline & 0.03 & $0.110 \pm 0.002$ & $94.7 \pm 2.1$ & 0.03 & $0.089 \pm 0.001$ & $103.6 \pm 0.6$ & 0.03 & $0.18 \pm 0.00$ & $91.9 \pm 2.2$ \\
\hline \multirow[t]{2}{*}{$\mathrm{Ce}$} & - & $0.13 \pm 0.00$ & & - & $0.092 \pm 0.001$ & & - & $0.24 \pm 0.01$ & \\
\hline & 0.03 & $0.16 \pm 0.00$ & $97.8 \pm 1.1$ & 0.03 & $0.122 \pm 0.002$ & $100.0 \pm 6.0$ & 0.03 & $0.27 \pm 0.01$ & $101.8 \pm 3.1$ \\
\hline \multirow[t]{2}{*}{$\operatorname{Pr}$} & - & $0.013 \pm 0.001$ & & - & $0.011 \pm 0.001$ & & - & $0.030 \pm 0.002$ & \\
\hline & 0.01 & $0.022 \pm 0.001$ & $94.8 \pm 5.2$ & 0.01 & $0.020 \pm 0.000$ & $95.4 \pm 2.6$ & 0.03 & $0.061 \pm 0.001$ & $102.2 \pm 2.6$ \\
\hline \multirow[t]{2}{*}{$\mathrm{Nd}$} & - & $0.058 \pm 0.003$ & & - & $0.041 \pm 0.001$ & & - & $0.12 \pm 0.01$ & \\
\hline & 0.03 & $0.088 \pm 0.001$ & $93.8 \pm 1.7$ & 0.03 & $0.072 \pm 0.004$ & $100.7 \pm 6.0$ & 0.03 & $0.15 \pm 0.00$ & $92.4 \pm 0.7$ \\
\hline \multirow[t]{2}{*}{$\mathrm{Sm}$} & - & $0.010 \pm 0.001$ & & - & $0.0074 \pm 0.0007$ & & - & $0.023 \pm 0.001$ & \\
\hline & 0.01 & $0.020 \pm 0.001$ & $93.6 \pm 3.3$ & 0.005 & $0.0125 \pm 0.0007$ & $103.1 \pm 5.9$ & 0.01 & $0.033 \pm 0.002$ & $97.2 \pm 5.0$ \\
\hline \multirow[t]{2}{*}{$\mathrm{Eu}$} & - & $0.0014 \pm 0.0002$ & & & $0.00082 \pm 0.0002$ & & - & $0.0047 \pm 0.0097$ & \\
\hline & 0.001 & $0.0025 \pm 0.0002$ & $104.2 \pm 6.9$ & 0.001 & $0.00172 \pm 0.0002$ & $91.0 \pm 9.1$ & 0.005 & $0.0092 \pm 0.0071$ & $91.0 \pm 7.7$ \\
\hline $\mathrm{Gd}$ & - & $0.013 \pm 0.001$ & & - & $0.011 \pm 0.002$ & & - & $0.026 \pm 0.0015$ & \\
\hline & 0.01 & $0.023 \pm 0.000$ & $96.1 \pm 1.3$ & 0.01 & $0.020 \pm 0.001$ & $93.9 \pm 5.7$ & 0.01 & $0.036 \pm 0.0018$ & $99.7 \pm 5.0$ \\
\hline $\mathrm{Tb}$ & - & $0.0019 \pm 0.0002$ & & - & $0.0018 \pm 0.0001$ & & - & $0.0050 \pm 0.0007$ & \\
\hline & 0.001 & $0.0029 \pm 0.0002$ & $104.3 \pm 6.8$ & 0.001 & $0.0028 \pm 0.0002$ & $95.2 \pm 9.1$ & 0.005 & $0.0100 \pm 0.0009$ & $99.6 \pm 9.1$ \\
\hline Dy & - & $0.0082 \pm 0.0009$ & & - & $0.011 \pm 0.001$ & & - & $0.024 \pm 0.001$ & \\
\hline & 0.005 & $0.0132 \pm 0.0010$ & $99.2 \pm 8.0$ & 0.01 & $0.021 \pm 0.001$ & $100.8 \pm 6.7$ & 0.01 & $0.033 \pm 0.003$ & $97.0 \pm 9.0$ \\
\hline Но & - & $0.0014 \pm 0.0004$ & & - & $0.0022 \pm 0.0001$ & & - & $0.0041 \pm 0.0007$ & \\
\hline & 0.001 & $0.0024 \pm 0.0001$ & $103.0 \pm 4.0$ & 0.001 & $0.0031 \pm 0.0001$ & $90.7 \pm 2.3$ & 0.005 & $0.0095 \pm 0.0009$ & $106.8 \pm 9.4$ \\
\hline $\mathrm{Er}$ & - & $0.0054 \pm 0.0009$ & & - & $0.0074 \pm 0.0005$ & & - & $0.015 \pm 0.001$ & \\
\hline & 0.005 & $0.0100 \pm 0.0003$ & $95.4 \pm 2.9$ & 0.005 & $0.012 \pm 0.001$ & $92.9 \pm 9.9$ & 0.01 & $0.024 \pm 0.002$ & $96.9 \pm 6.2$ \\
\hline $\mathrm{Tm}$ & - & $0.00056 \pm 0.00011$ & & - & $0.00049 \pm 0.00011$ & & - & $0.0018 \pm 0.0001$ & \\
\hline & 0.001 & $0.00150 \pm 0.00013$ & $94.0 \pm 8.6$ & 0.001 & $0.0159 \pm 0.00009$ & $109.9 \pm 6.7$ & 0.001 & $0.0028 \pm 0.0001$ & $103.8 \pm 3.8$ \\
\hline $\mathrm{Yb}$ & - & $0.0079 \pm 0.0004$ & & - & $0.0069 \pm 0.0003$ & & - & $0.012 \pm 0.001$ & \\
\hline & 0.005 & $0.0129 \pm 0.0008$ & $101.8 \pm 6.2$ & 0.005 & $0.0123 \pm 0.0005$ & $104.8 \pm 3.9$ & 0.01 & $0.022 \pm 0.003$ & $100.8 \pm 9.1$ \\
\hline $\mathrm{Lu}$ & - & $0.0013 \pm 0.0001$ & & - & $0.0011 \pm 0.0000$ & & - & $0.0012 \pm 0.0001$ & \\
\hline & 0.001 & $0.0024 \pm 0.0001$ & $109.4 \pm 5.7$ & 0.001 & $0.00211 \pm 0.0001$ & $101.9 \pm 6.4$ & 0.001 & $0.0022 \pm 0.0002$ & $94.0 \pm 6.2$ \\
\hline
\end{tabular}

a. Sample volume, $50 \mathrm{~mL}$; eluent, $10 \mathrm{~mL}$ (5-fold preconcentration factor); 3 replicates, except for $\mathrm{Al}$ and $\mathrm{Mn}$. b. Sample volume, $10 \mathrm{~mL}$; eluent, $10 \mathrm{~mL}$ (1-fold preconcentration factor); 3 replicates. c. Samples were digested using $\mathrm{HNO}_{3}$ and $\mathrm{HCl}$ (based on EPA Method 200.8) before passing through the column.

25. K. Oshita, Y. Gao, M. Oshima, and S. Motomizu, Anal. Sci., 2001, 17(Supplement), a317.

26. S. J. Hill, "Inductively Coupled Plasma Spectrometry and Its Applications", 1999, Sheffield Academic Press Ltd., England, 23.

27. S. E. Long and T. D. Martin, in Method 200.10 Determination of Trace Elements in Marine Waters by OnLine Chelation Preconcentration and Inductively Coupled Plasma-Mass Spectrometry, 1997, United States Environmental Protection Agency, Ohio, USA.

28. W. Stumm and J. J. Morgan, "Aquatic Chemistry", 3rd ed., 1996, Wiley Interscience Publication, John Wiley \& Sons, Inc., New York.

29. T. J. Ward and J. R. Kramer, Comp. Biochem. Physiol., Part C: Toxicol. Pharmacol., 2002, 133, 75.

30. R. K. Katarina, T. Takayanagi, M. Oshima, and S. Motomizu, Anal. Chim. Acta, 2006, 558, 246

31. Y. Sun, C. J. Anderson, T. S. Pajeau, D. E. Reichert, R. D. Hancock, R. J. Motekaitis, A. E. Martell, and M. J. Welch, J. Med. Chem., 1996, 39, 460.

32. C. A. Brockhoff, J. T. Creed, T. D. Martin, E. R. Martin, and S. E. Long, in Method 200.8 Revision 5.5
Determination of Trace Elements in Waters and Wastes by Inductively Coupled Plasma-Mass Spectrometry, 1999, United States Environmental Protection Agency, Washington, USA.

33. J. W. Robinson, "Handbook of Spectroscopy", 1974, Vol. II, CRC Press Inc., Boca Raton, 75.

34. D. Bilba, D. Bejan, and L. Tofan, Croat. Chem. Acta, 1998 , 71,155 .

35. V. Camel, Spectrochim. Acta, Part B, 2003, 58, 1177.

36. R. Lobonski and Z. Marczenko, "Comprehensive Analytical Chemistry, Vol. XXX: Spectrochemical Trace Analysis for Metals and Metalloids", 1996, Elsevier Science B. V., The Netherlands.

37. K. S. Leonard, D. McCubbin, and B. R. Harvey, Sci. Total Environ., 1923, 130 - 131, 237.

38. I. Komjarova and R. Blust, Anal. Chim. Acta, 2006, 576, 221.

39. A. Deepatana, J. A. Tang, and M. Valix, Miner. Eng., 2006, 19,1280 .

40. V. Thomsen, D. Schatzlein, and D. Mercuro, Spectroscopy, 2003, 18, 112.

41. IUPAC Compendium of Chemical Terminology-The Gold Book (http://goldbook.iupac.org/L03540.html). 